\title{
Diagnosis and Management of Submandibular Sialolithiasis
}

\author{
Ginni Datta1, Saima Tabbasum², L. N. Garg³, Amit Mittal4
}

\begin{abstract}
1Department of ENT, MM Institute of Medical Sciences and Research, Maharishi Markandeshwar (Deemed to be University), Mullana, Ambala, Haryana, India. ${ }^{2}$ Department of ENT, MM Institute of Medical Sciences and Research, Maharishi Markandeshwar (Deemed to be University), Mullana, Ambala, Haryana, India. ${ }^{3}$ Department of ENT, MM Institute of Medical Sciences and Research, Maharishi Markandeshwar (Deemed to be University), Mullana, Ambala, Haryana, India. ${ }^{4}$ Department of Radiodiagnosis, MM Institute of Medical Sciences and Research, Maharishi Markandeshwar (Deemed to be University), Mullana, Ambala, Haryana, India.
\end{abstract}

\section{ABSTRACT}

\section{BACKGROUND}

Submandibular gland is the most common site of stone formation among all the salivary glands, owing to its long duct, mucus rich saliva and antigravity flow. Swelling and pain on eating is its most common presentation. Most salivary stones are made up of calcium phosphates, and only a few contain pure organic material. Surgical removal is required, and the route of surgery is planned according to the site and size of the stone.

\section{METHODS}

We conducted a cross sectional study on 25 consecutive patients with a clinical diagnosis of submandibular sialolithiasis. Thorough history taking and clinical examination was followed by ultrasound scan to confirm the diagnosis and establish the site and size of the stone. Stone procured after removal was analysed chemically in the biochemistry laboratory.

\section{RESULTS}

Out of 25 patients, calculi in 11 cases were found in the intraglandular part of the submandibular gland and in 14 cases in the intraductal part of the gland. Out of the 14 cases with stone in the intraductal part, in 4 cases the stone was removed with the help of sialagogues and milking due to the very small size of the stone; whereas, in 10 cases the stone was removed intraorally with marsupialisation of the duct under local anaesthesia. In 11 cases the gland had to be removed along with the stone. As per the biochemical analysis, calcium and phosphate stones were the commonest in our study followed by oxalate calculi. Obtained results showed that the studied salivary stones had almost $10 \%$ association with nephrolithiasis. The salivary $\mathrm{pH}$ was acidic in 10 cases and alkaline in 15 cases.

\section{CONCLUSIONS}

Characteristic history, thorough clinical examination and ultrasonic examination help us in the diagnosis of sialolithiasis. The site and size of the calculus is the deciding factor for the surgical plan. Biochemically stones are invariably composed of calcium and phosphates. Simultaneous occurrence of sialoliths and renal calculi was purely by chance or as a comorbidity needs to be studied more in a larger study group.
Corresponding Author:

Dr. L. N. Garg,

Professor,

Department of ENT,

MM Institute of Medical Sciences and

Research, Maharishi Markandeshwar (Deemed to be University), Mullana,

Ambala-133207, Haryana, India.

E-mail:dr.ingarg@gmail.com

DOI: 10.14260/jemds/2020/247

Financial or Other Competing Interests: None.

How to Cite This Article:

Datta G, Tabbasum S, Garg LN, et al. Diagnosis and management of submandibular sialolithiasis. J. Evolution Med. Dent. Sci. 2020;9(14):1140-1143, DOI: 10.14260/jemds/2020/247

Submission 13-12-2019,

Peer Review 15-03-2020,

Acceptance 21-03-2020,

Published 06-04-2020.

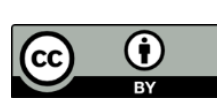

\section{KEY WORDS}

Sialolithiasis, Submandibular Gland, Calcium 


\section{BACKGROUND}

Sialolithiasis (salivary gland stones) is one of the most common diseases of the salivary glands with a prevalence of $1.2 \%$. Males are affected twice as often as females. ${ }^{1}$ The most common site of stone formation is the submandibular gland followed by parotid gland. ${ }^{2}$ Submandibular calculi are more frequent as the $\mathrm{pH}$ of its saliva is more alkaline, and has more concentration of minerals like calcium and phosphate. Its saliva has a much more mucous content than saliva of other salivary glands. Also, the submandibular duct is much longer and the gland has a flow against gravity when compared with parotid gland.

Hallmark feature of sialolithiasis is episodic pain and swelling during meals which may last for a few hours, with interim symptom free periods. The commonest symptom in submandibular sialadenitis is swelling and next to follow is pain. Swelling and pain are more prominent when a stone is stuck in the duct than when the stone is in the gland itself. ${ }^{3}$ Salivary stones can range in size from tiny particles to several centimeters in length; the largest reported stone in the submandibular duct was $72 \mathrm{~mm}$ in length. ${ }^{4}$ Simultaneous sialolithiasis of more than one gland at the same time is rare. 5

In the studies of sialoliths it has been observed that the mineral composition of sialoliths found in Wharton's duct differ from those found in other intraglandular ducts; this may imply that the ionic environment may differ in different ducts. ${ }^{6}$ Both organic and inorganic salts make up a sialolith. The organic part varies from 23 to $100 \%$ and is mainly concentrated in the nucleus and the outer shell of the stone. Only a few sialoliths are made up of organic material alone; most salivary stones are made up of inorganic minerals like calcium phosphates, either as hydroxyapatite or carbonate apatite.

Submandibular stones contain less organic materials as compared to parotid gland stones. Various imaging techniques are available for the diagnostic investigation. One method of choice is B-mode ultrasound scanning. This noninvasive procedure allows stones of $1.5 \mathrm{~mm}$ or more in diameter to be detected with a sensitivity of $95 \%$ to $99.5 \%$. If sialolithiasis is suspect clinically, ultrasonography with a linear scanner must be considered the investigation of choice. Sialography, computed tomography (CT), and magnetic resonance imaging (MRI) are more time-consuming, require radiation exposure, require contrast medium administration, and have higher costs and are therefore used for more complicated cases such as associated abscess. Diagnostic salivary gland endoscopy (SGE), on the other hand, has increased in importance in recent years and fills the diagnostic gap by allowing the direct visualization of stones.7,8

For very small stones or concretions within the duct management protocol consists of gland massage and milking. Antibiotics are to be given whenever infection is suspected. Almost all intraductal submandibular stones can be removed by an intraoral approach under local anaesthesia. The simple method of intraoral removal is treatment of choice in patients where stones that can be palpated bimanually. After stone removal, it is recommended that salivary gland massage is carried out several times a day, combined with a sour diet and sialagogues to stimulate the salivary flow.

Invasive management of sialolithiasis for recurrent attacks of sialadenitis because of the presence of stone in the gland itself is surgical removal of the gland. Though surgery has been the norm for years, nonsurgical methods are becoming more common. Endoscopy is a very helpful tool to fill the diagnostic gap in detecting Sialoliths 9 . Sialendoscopy using a micro endoscope can be used on an outpatient basis and without general anaesthesia or sedation. Sialendoscopy using a micro endoscope can be used on an outpatient basis and without general anaesthesia or sedation of. Extracorporeal salivary lithotripsy, based on the extracorporeal shock-wave lithotripsy (ESWL) method of treating renal calculi, carries fewer risks than the surgical approach. ${ }^{10} \mathrm{~A}$ basket extractor under fluoroscopic guidance may be used to extract stone fragments that fail to pass after lithotripsy. ${ }^{11}$ If a stone is detected, a laser fiber is advanced until the tip just touches the stone. With laser-induced shock waves (LASER lithotripsy), the stone is fragmented. The disintegrated stone particles can be flushed out by the clinician, or may flush out with the restored salivary flow. ${ }^{12}$

We wanted to determine the incidence of calculus in various sites in relation to submandibular gland and determine the biochemical composition of the calculus.

\section{METHODS}

It was a cross sectional study carried out in ENT and Biochemistry department of MMIMSR. A total of 25 consecutive patients on basis of convenient sampling with clinical and ultrasonic evidence of submandibular duct or gland calculus were taken for study. Informed written consent was taken from all the patients. Patients with a clinically evidence of submandibular duct or gland calculus after confirmation by ultrasonography. According to Performa, detailed history was taken; thorough general and local examination was carried out in all the patients to arrive at a provisional diagnosis. Clinical examination was followed by ultrasound scan to confirm the diagnosis. Associated history for co-morbidity like renal calculi was taken and where required ultrasound abdomen was also done. Patients were managed either by giving a course of antibiotics, adequate hydration, warm compresses and sialagogues or by surgery depending upon the clinical examination and ultrasound findings. Stones removed during surgery were sent for biochemical analysis, where each calculus was washed with distilled water and dried completely in incubator. The stones were crushed into fine powder and the analysis was done for oxalates, calcium, phosphate, carbonates and uric acid by protocols described by Hodgkinson. Analysis of salivary $\mathrm{pH}$ was done in the Department of Biochemistry. The patients were kept nil orally for 2 hours. Patients were asked to collect the saliva in mouth \& swallow it. This was repeated twice, then the third time, some saliva was put onto the litmus paper. The colour of the litmus paper was noted, and $\mathrm{pH}$ was recorded.

Statistical analysis was performed using the IBM SPSS statistical Software Version. 22.0

\section{RESULTS}

In our study of 25 patients 14 were males and 11 were females. Majority of the patients were middle aged in the age group of 
31-40 years followed by $41-50$ years. The calculi in 11 cases were found in the intraglandular part of the submandibular gland and in 14 cases in the calculus was in the intraductal part. Regarding the biochemical analysis, calcium and phosphate stones were the commonest in our study followed by oxalate calculi [Table 1]. Obtained results showed that the studied salivary stones had an almost $10 \%$ association with nephrolithiasis. In our case the salivary $\mathrm{pH}$ was acidic in 10 cases and in 15 cases the $\mathrm{pH}$ was alkaline. In 4 cases the stone was removed with the help of sialagogues and milking. In 11 cases the gland had to be removed and in 10 cases the stone was removed intraorally with marsupialisation of the duct under local anaesthesia [Table 2]

\begin{tabular}{|c|c|c|}
\hline Predominant Chemical Composition & No. of Cases & Percentage (\%) \\
\hline Calcium & 25 & 100 \\
\hline Oxalate & 21 & 84 \\
\hline Phosphate & 25 & 100 \\
\hline Carbonate & 01 & 2 \\
\hline Uric acid & 01 & 2 \\
\hline \multicolumn{3}{|c|}{ Table 1. Predominant Calculus Composition with Number of Cases } \\
\hline Surgical Manipulation & \multicolumn{2}{|c|}{ Non-Invasive Treatment } \\
\hline Submandibular Gland Excision $=11$ & \multicolumn{2}{|c|}{ Milking of DUCT $=4$} \\
\hline $\begin{array}{c}\text { Intraoral Removal of Stone with } \\
\text { Marsupialization of DUCT }=10\end{array}$ & & \\
\hline \multicolumn{3}{|c|}{ Table 2. Management of Patients with Sialolithiasis } \\
\hline
\end{tabular}

\section{DISCUSSION}

Kopec and colleagues (2011) ${ }^{13}$ stated that nearly $5 \%$ of patients come to the ENT specialist with salivary gland pathology symptoms. Chronic sialadenitis is one of the commonest disorder that presents as recurrent episodes of infection and results in salivary hypo function. Diagnosis and management result in good recovery. Sialolithiasis can be diagnosed by careful consideration of history taking of patient illustrating typical symptoms and thorough clinical examination. Ultrasonography confirmed all our cases and as suggested by other authors is the investigation of choice.14,15 In our study there was a male to female predilection. Sialoliths predominantly affected middle age individuals in the age group of 30 to 40 and 40 to 50 years.

Zenk $\mathrm{J}^{15}$ in his study Clinical and diagnostic findings of sialolithiasis concluded that Sialoliths occurred most frequently in patients aged 30 and 70 years, with no male or female predilection. Taher AA ${ }^{16}$ in his study of 95 patients with sialolithiasis observed male to female ratio of 2.5:1. In our study of all submandibular swellings Sialadenitis with duct calculus was more common than patients of sialadenitis with Intra-glandular calculus. S Kraaij et al ${ }^{17} 2014$ in his study concluded that the majority of the submandibular stones are located in Wharton's duct (90\%), as contrast to parotid stones which are commonly located in the gland itself.

The main bulk of sialoliths is inorganic material. Submandibular stones are made up of $70-80 \%$ inorganic material. The mineral component increases proportional to the size of the sialolith, indicating that mineralization over the nucleus of organic matrix increases with time. Regarding the biochemical analysis, calcium and phosphate stones were the commonest in our study followed by oxalate calculi.
Taher $\mathrm{AA}^{16}$ in his study of 95 patients with sialolithiasis did Chemical analysis of calculi taken from 88 patients, showed that 89.77 percent were with phosphate salts stones, 7.98 per cent were with oxalate salts, and 2.27 per cent were with urate salts which is comparable to our study. Hiraide $\mathrm{F}^{18}$ concluded that minerals like calcium, phosphorous, potassium, sodium, magnesium, chlorine, sulphur, manganese; chromium and aluminium are equally distributed in the substance of the calculus. Also, obtained results show that the studied salivary stones had an almost $10 \%$ association with nephrolithiasis. Lustmann et $\mathrm{al}^{2}$ found an incidence of renal stones of $10.7 \%$ in patients with sialolithiasis, which was higher than the incidence in the general population group. However Zenk $\mathrm{J}^{15}$ in his study Clinical and diagnostic findings of sialolithiasis concluded that a simultaneous urinary tract stone or stone of the biliary tract occurred by mere chance (4.3\%). Several studies suggested that patients with sialoliths suffer more frequently from renal calculi or gallbladder stones ${ }^{2}$. More studies with larger sample size are required to ascertain the association of renal calculi with sialoliths.

The salivary fluid, over $99 \%$ is made up of water. Saliva as a whole collected from the mouth apart from containing secretions of all the salivary glands also contains desquamated epithelial cells from oral cavity, normal flora of oral cavity, leucocytes, serum constituents and food particles. Major production of the saliva is from the Submandibular gland $(60 \%)$ followed by Parotid gland (30\%), about $5 \%$ by sublingual gland and $7 \%$ by minor salivary glands. The saliva that rests and forms a pool in the mouth determines the environment of the oral cavity. The normal $\mathrm{pH}$ range of saliva is 6.2-7.6 and 6.7 is the average $\mathrm{pH}$. The resting $\mathrm{pH}$ of mouth does not fall below 6.3. In the oral cavity, the $\mathrm{pH}$ is maintained near neutrality (6.7-7.3) by saliva. The saliva helps to maintain a near neutral ph. The regular flow of saliva constantly keeps moving the food bolus that could be broken down by bacteria. Acidity from drinks, foods and bacterial activity, is neutralized by the buffering action of saliva.

In our case the predominant $\mathrm{pH}$ was acidic in 10 cases and alkaline in 15 cases. Lustmann ${ }^{19}$ observed that there was continuous appositional growth of calcified layers around one central nidus. They also emphasized the role of microorganisms in the formation of calculi. The key to management of salivary stones is on removing the salivary stones and at the same time preserve the salivary gland function dependent on the size and location of the stone. Conservative management of small salivary stones in form of salivary gland massage, milking and the use of sialagogues helped in expulsion of small stones in 4 cases. In 10 cases intraoral removal of stone with marsupialisation of duct was done under local anesthesia as part of day care surgery. In 11 cases Submandibular gland excision was done.

\section{CONCLUSIONS}

Characteristic history, thorough clinical examination and ultrasonic examination help us in the diagnosis of sialolithiasis. The site and size of the calculus is the deciding factor for the surgical plan. Biochemically stones are invariably composed of calcium and phosphates. Simultaneous occurrence of sialoliths and renal calculi was purely by chance 
or as a comorbidity needs to be studied more in a larger study group.

\section{REFERENCES}

[1] Rani ASR, Suragimath G, Bijjaragi S, et al. Mealtime syndrome: an enigma to resolve. J Adv Med Dent Sci 2014;2(1):120-3.

[2] Lustmann J, Regev E, Melamed Y. Sialolithiasis: a survey on 245 patients and a review of the literature. Int J Oral Maxillofac Surg 1990;19(3):135-8.

[3] Levy DM, Remine WH, Devine KD. Salivary gland calculi: pain, swelling associated with eating. J Am Med Assoc 1962;181(13):1115-9.

[4] Rai M, Burman R. Giant submandibular sialolith of remarkable size in the comma area of Wharton's duct: a case report. Oral Maxillofac Surg 2009;67(6):1329-32.

[5] Teymoortash A, Ramaswamy A, Werner JA. Is there evidence of a sphincter system in Wharton's duct? Etiological factors related to sialolith formation. J Oral Sci 2003;45(4):233-5.

[6] Teymoortash A, Buck P, Jepsen H, et al. Sialolith crystals localized intraglandularly and in the Wharton's duct of the human submandibular gland: and X-ray diffraction analysis. Arch Oral Biol 2003;48(3):233-6.

[7] Fodra C, Kaarmann H, Iro H. Sonography and plain roentgen image in diagnosis of salivary calculiexperimental studies [in German]. HNO 1992;40(7):25965.

[8] Zenk J, Iro H, Klintworth N, et al. Diagnostic imaging in sialadenitis. Oral Maxillofac Surg Clin North Am 2009;21(3):275-92.
[9] Zenk J, Gottwald F, Bozzato A, et al. Submandibular sialoliths. Stone removal with organ preservation. HNO 2005;53(3):243-9.

[10] Iro H, Schneider HT, Froda C, et al. Shockwave lithotripsy of salivary duct stones. Lancet 1992;339(8805):1333-6.

[11] Drage NA, Brown JE, Escudier MP, et al. Interventional radiology in the removal of salivary calculi. Radiology 2000;214(1):139-42.

[12] Gundlach P, Scherer H, Hopf J, et al. Die endoskopischkontrollierte Laserlithotipsie von Speichelsteinen. In-vitro Untersuchungen und erster Klinischer Einsatz. HNO 1990;38:247-50.

[13] Kopec T, Wierzbicka M, Szyfter W. A proposal for the classification of chronic sialadenitis of the major salivary glands with current diagnostic and treatment schedule. Otolaryngol Pol 2011;65(3):188-93.

[14] Gritzmann N. Sonography of the salivary glands. AJR American J Roentgenol 1989;153(1):161-6.

[15] Zenk J, Constantinidis J, Kydles S, et al. Clinical and diagnostic findings of sialolithiasis. HNO 1999;47(11):963-9.

[16] Taher AA. The incidence and composition of salivary stones (sialolithiasis) in Iran: analysis of 95 cases--a short report. Singapore Dent J 1989;14(1):33-5.

[17] Kraaij S, Karagozoglu KH, Forouzanfar T, et al. Salivary stones: symptoms, aetiology, biochemical composition and treatment. Br Dent J 2014;217(11): E23.

[18] Hiraide F, Nomura Y. The fine surface structure and composition of salivary calculi. Laryngoscope 1980;90(1):152-8.

[19] Lustmann J, Shteyer A. Salivary calculi: ultrastructural morphology and bacterial etiology. J Dent Res 1981;60(8):1386-95. 